Rapid Reviews COVID-19•

\title{
Reviews of "A year of genomic surveillance reveals how the SARS-CoV- 2 pandemic unfolded in Africa"
}

M Hossain', Adriana Heguy ${ }^{2}$

${ }^{1}$ University of Dhaka: Dhaka University Microbiology BANGLADESH,

${ }^{2}$ NYU Langone Medical Center: NYU Langone Health Pathology UNITED STATES

Published on: Aug 30, 2021

License: Creative Commons Attribution 4.0 International License (CC-BY 4.0). 
To read the original manuscript, click the link above.

Summary of Reviews: This preprint explores the genetic changes of SARS-CoV-2 in Africa by offering an in-depth epidemiological analysis of virus introduction, circulation, and evolution over a year. Reviewers agree that the claims are reliable and supported by the data.

\section{Reviewer 1 (M Hossain) | प्र०ण}

\section{Reviewer 2 (Adriana Heguy) | प्र०००}

\section{RR:C19 Strength of Evidence Scale Key.}

$$
\begin{aligned}
& \text { प }
\end{aligned}
$$

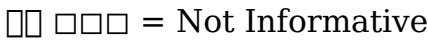

$$
\begin{aligned}
& \text { प्रा पर = Potentially Informative }
\end{aligned}
$$

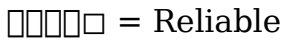

$$
\begin{aligned}
& \text { प्राप्र = Strong }
\end{aligned}
$$

To read the reviews, click the links below. 